Supporting Information:

\title{
Fabrication of Surface Plasmon Resonators by Nanoskiving Single-Crystalline Gold Microplates
}

Benjamin J. Wiley ${ }^{1}$, Darren J. Lipomi ${ }^{1}$, Jiming Bao ${ }^{2}$, Federico Capasso ${ }^{2}$, George M. Whitesides ${ }^{1, *}$

1. Department of Chemistry and Chemical Biology

2. Harvard School of Engineering and Applied Sciences

Harvard University, 12 Oxford St., Cambridge, MA 02138, U.S.A.

* Author to whom correspondence should be addressed 


\section{EXPERIMENTAL SECTION:}

\section{Materials}

Epo-fix epoxy resin and hardener were purchased from Electron Microscopy Sciences. $\mathrm{HAuCl}_{4}$ and polyvinylpyrrolidone (PVP, MW=55,000) were purchased from Aldrich. Ethylene glycol (EG) was purchased from J.T. Baker.

\section{Synthesis of Microplates}

To grow microplates of gold, we heated $5 \mathrm{~mL}$ of EG in a disposable glass vial submerged in an oil bath set to $160{ }^{\circ} \mathrm{C}$ for 1 hour before adding $0.83 \mathrm{ml}$ of $0.2 \mathrm{M} \mathrm{HAuCl} 4$ in $\mathrm{EG}$ and $2.5 \mathrm{ml}$ of a $222 \mathrm{mg} / \mathrm{mL}$ solution of PVP (MW=55,000) in EG. We heated this mixture with stirring for about 1 hour before stopping the reaction, at which time the solution contained a mixture of microplates and nanoparticles. We then immediately added the reaction mixture to $10 \mathrm{~mL}$ of a $0.25 \mathrm{~g} / \mathrm{mL}$ solution of PVP in ethanol. After mixing, we layered this suspension of gold microplates and nanoparticles on top of $30 \mathrm{ml}$ of a 0.25

$\mathrm{g} / \mathrm{mL}$ aqueous solution of PVP. Over the course of $6 \mathrm{hrs}$, the larger microplates settled to the bottom of the centrifuge tube while the nanoparticles stayed in the top ethanol phase. We then discarded the supernatant and resuspended the microplates in a $0.25 \mathrm{~g} / \mathrm{mL}$ aqueous solution of PVP.

Procedure for Nanoskiving Microplates 
The procedure for nanoskiving microplates is illustrated in Figure 1. We first deposited them from solution onto a thin $(1, \mathrm{w}, \mathrm{h} \sim 2 \mathrm{~cm}, 2 \mathrm{~cm}, 2 \mathrm{~mm}$ ) slab of epoxy (Epo-fix, obtained from Electron Microscopy Sciences). After drying, we immersed the slab with microplates in deionized water to wash away the PVP, being careful not to wash the microplates off the slab as well. After drying a second time, the slab with microplates was cut into thin strips with a razor blade. These strips were placed in polyethlyene molds, embedded in epoxy prepolymer and cured to form epoxy blocks. After trimming away excess epoxy, these blocks were sectioned into 50-nm-thick slices. Readers are referred to the supplementary information of our previous work for a detailed description of microtome section alignment (8).

\section{Microscopy}

Dark-field optical microscopy was performed with a Leica DMRX upright optical microscope. Epoxy slabs containing nanowires were placed on pieces of a Si wafer for scanning electron microscopy, and on a carbon-coated copper grid for transmission electron microscopy. SEM images were acquired with a Zeiss Supra55VP field emission scanning electron microscope operated at $5 \mathrm{kV}$. For imaging of freestanding gold nanowires, epoxy sections were etched by oxygen plasma (1 Torr, $70 \mathrm{~W}$ barrel etcher) for 40 min. TEM images were acquired with a Jeol JEM-2100 LaB6 transmission electron microscope operated at $200 \mathrm{kV}$. 